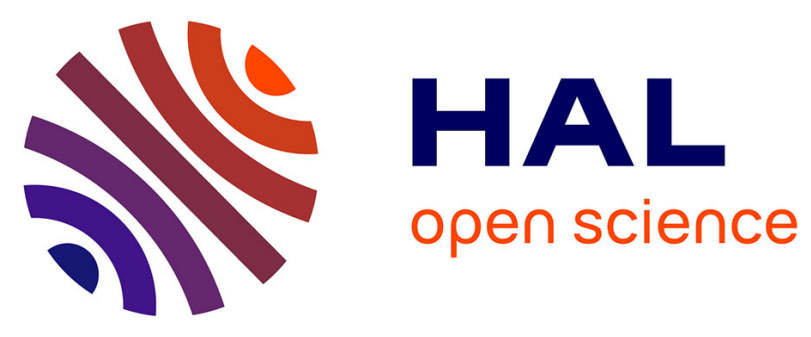

\title{
Additional Efficient Warning Sounds for Electric and Hybrid Vehicles
}

Etienne Parizet, Ryan Robart, Perceval Pondrom, Jean-Christophe Chamard, Guillaume Baudet, David Quinn, Karl Janssens, Manfred Haider

\section{To cite this version:}

Etienne Parizet, Ryan Robart, Perceval Pondrom, Jean-Christophe Chamard, Guillaume Baudet, et al.. Additional Efficient Warning Sounds for Electric and Hybrid Vehicles. Michel André, Zissis Samaras. Energy and Environment, 1, Wiley, pp.501-510, 2016, 9781786300263. 10.1002/9781119307761.ch32 . hal-01917273

\section{HAL Id: hal-01917273 https://hal.science/hal-01917273}

Submitted on 9 Nov 2018

HAL is a multi-disciplinary open access archive for the deposit and dissemination of scientific research documents, whether they are published or not. The documents may come from teaching and research institutions in France or abroad, or from public or private research centers.
L'archive ouverte pluridisciplinaire $\mathbf{H A L}$, est destinée au dépôt et à la diffusion de documents scientifiques de niveau recherche, publiés ou non, émanant des établissements d'enseignement et de recherche français ou étrangers, des laboratoires publics ou privés. 


\title{
Additional efficient warning sounds for electric and hybrid vehicles
}

\author{
Parizet E. ${ }^{\text {a }}$, Robart R. ${ }^{\text {a }}$, Pondrom P. ${ }^{\text {b }}$, Chamard J.C. ${ }^{\text {c, }}$ \\ Baudet G. ${ }^{\mathrm{d}}$, Quinn D. ${ }^{\mathrm{e}}$, Janssens K. ${ }^{\mathrm{f}}$ Haider M. ${ }^{\mathrm{g}}$ \\ ${ }^{a}$ Laboratoire Vibrations Acoustique, INSA-Lyon, Villeurbanne, France \\ ${ }^{b}$ Technical University Darmstadt, Darmstadt, Germany \\ ${ }^{c}$ PSA Peugeot Citroën, Vélizy-Villacoublay, France \\ ${ }^{d}$ Renault, Guyancourt, France \\ ${ }^{e}$ Nissan, Sunderland, United Kingdom \\ ${ }^{f}$ LMS International, Leuven, Belgium \\ ${ }^{g}$ Austrian Institute of Technology, Vienna, Austria
}

\begin{abstract}
Electric or hybrid vehicles are very silent, which represents a major advantage for the reduction of noise annoyance in urban areas. But this makes them dangerous for pedestrians, especially vulnerable ones as visuallyimpaired people. Current solutions consist in using warning sound so that the exterior noise of an electric vehicle is as high as for a conventional one. This may cancel the benefit of electric vehicles for the reduction of sound annoyance. The eVADER project (funded by the European Commission) aims at proposing a prototype car which combines a high safety and a low noise level. A part of the the work program consisted in perceptual studies. The goal of these studies was to evaluate the influence of various timbre parameters on the detectability and the unpleasantness of a warning sound. Results show that it is possible to make an electric vehicle easily detected while keeping its sound level much lower than the one of a conventional car.
\end{abstract}

Keywords: electric vehicles, noise, warning sounds, safety, noise environment.

\section{Résumé}

Les véhicules électriques ou hybrides sont très silencieux, ce qui représente un avantage dans la lutte pour la réduction de la gêne sonore en milieu urbain. Mais ceci les rend également dangereux pour les piétons, les personnes vulnérables tels que les non-voyants étant particulièrement concernées. Les solutions actuellement proposées consistent à ajouter à ces véhicules des signaux d'alerte les rendant aussi sonores que des véhicules conventionnels, ce qui annule l'avantage pour l'environnement. Le projet eVADER, soutenu par la Commission Européenne, veut proposer un prototype permettant de combiner une bonne sécurité et un niveau de bruit réduit. Parmi les travaux réalisés, des études perceptives ont permis d'évaluer l'influence de divers paramètres du timbre d'un signal d'alerte sur la détectabilité du véhicule et le désagrément du bruit. Les résultats montrent qu'il est possible de parvenir à une bonne détectabilité d'un véhicule électrique en lui conservant un niveau sonore très nettement inférieur à celui d'une automobile conventionnelle.

Mots-clé: véhicules électriques, bruit, signal d'alarme, sécurité, environnement sonore.

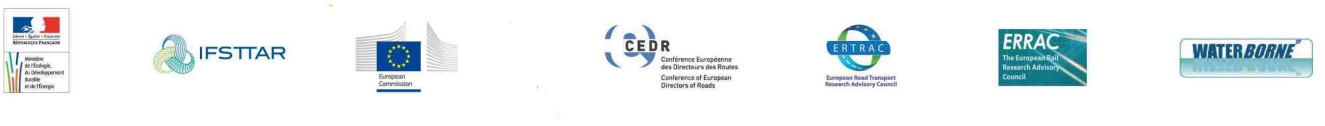




\section{Introduction}

Electric and hybrid vehicles are very quiet at low speeds (typically below $30 \mathrm{~km} / \mathrm{h}$ ). The level of the noise emitted by such vehicles is 5 to $7 \mathrm{~dB}(\mathrm{~A})$ lower than the one of conventional Diesel cars. This is very beneficial to people living in an urban area, because transportation noise is a major source of annoyance in cities. On the other hand, this represents a hazard for pedestrian, who may not hear an approaching car. Vulnerable people as visually-impaired ones have a very strong concern about such cars and manufacturers use additional warning sounds in order to prevent this risk. Though several studies have already been conducted in that field (e.g. Yamauchi et al., 2011, or Emerson et al., 2012), the easiest way to solve this safety issue is to use loud warning sounds, which cancels the noise reduction advantage of electric cars. Regulations, either already decided (NHTSA) or under preparation (in Europe), go this way. As an example, the regulation currently prepared in Europe states that "the (warning) sound level may not exceed the sound level of a similar internal combustion engine vehicle". It should be possible to use more efficient warning sounds.

The eVADER project brings together partners from universities, research centers, car manufacturers and a supplier. Last but not least, the European Blind Union is a partner, so that end users are represented in the consortium. The goal of this project is to develop a prototype vehicle combining a high safety for pedestrian and a low noise annoyance for city residents. Several technical solutions are developed :

- An automatic pedestrian detection device;

- A set of loudspeakers focusing the sound in the direction of the detected pedestrian;

- A warning sound designed so that it can be detected in an urban environment at a low level.

This paper will describe studies focusing on this third objective. It will present three listening test experiments : two of them aimed at evaluating the influence of some timbre parameters on the detectability and annoyance of warning sounds. A third one intended to determine whether some information about the speed of the car can be evoked by the warning sound, without any training of the listener.

These three experiments were simultaneously conducted by various partners of the project, which allowed to use large subjects samples.

\section{Detectability}

The first part of the study was related to the detectability of warning sounds. Given the background traffic noise of an urban environment, is it possible to make a warning sound easily detectable in spite of a low level ? It was decided to limit the study to multi-tone sounds, in a middle frequency range $(300-1500 \mathrm{~Hz})$. The lowest frequency was due to technical limitation of the loudspeakers to be used in the prototype (for a high radiation efficiency at low frequencies, very large loudspeakers would have been necessary). And the high frequency limit was selected because people suffering from presbyacousis have high hearing thresholds at higher frequencies.

\subsection{Procedure}

In this experiment, three timbre factors were investigated : the number of tones, the frequency variation and the temporal variation. Each factor could have three levels : as an example, the number of tones could be 3, 6 or 9 . A fractional factorial design was used, so that 9 combinations were used (instead of 27 in a full factorial design). More details about the stimuli definition can be found in Robart et al. (2013).

Therefore, 9 stimuli were synthesized; they all had the same A-weighted level. Then they were modified in order to represent a moving source, passing in front of a listener at the speed of $20 \mathrm{~km} / \mathrm{h}$. Finally, each modified stimulus was added to the recording of an electric vehicle recorded at $20 \mathrm{~km} / \mathrm{h}$ by a dummy head located close to the road. This way, it was possible to simulate the situation of a pedestrian facing the road, waiting to cross this road and paying attention to any approaching car (figure 1). 


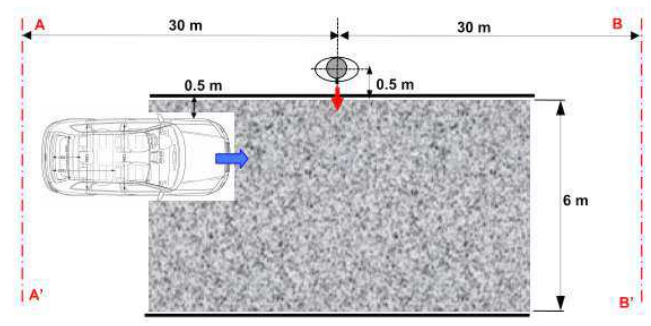

Fig. 1. "Waiting to cross" scenario

The recording of the electric vehicle alone as well as the one of a similar diesel car were added to this set of stimuli. The level of warning sounds were adjusted so that they increase the level of the electric vehicle very slightly (less than $2 \mathrm{~dB}(\mathrm{~A})$, see figure 2). The level of the diesel car was higher by more than $5 \mathrm{~dB}(\mathrm{~A})$.

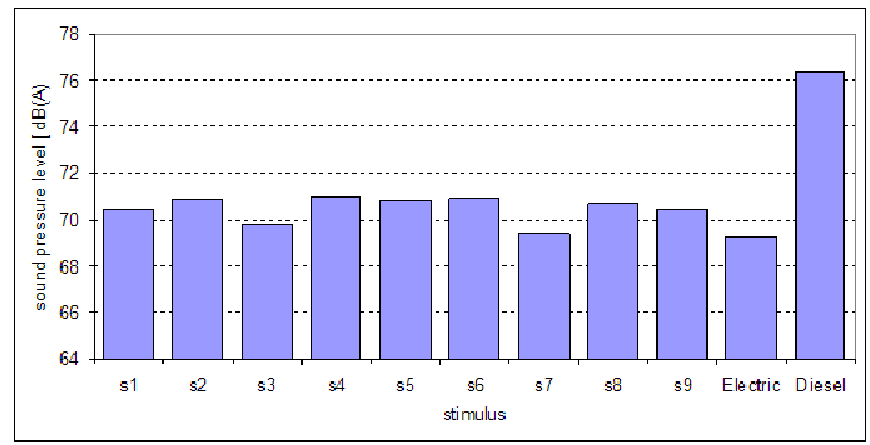

Fig. 2. Peak level (A-weighted SPL) of each stimulus used in experiment 1

During the experiment, the listener was hearing a background traffic noise through headphones. Rain noise was added, as this represents a very difficult situation for blind pedestrian. The level of this noise was $69 \mathrm{~dB}(\mathrm{~A})$. At randomly selected times, one of the car stimuli was added to the noise. This car could arrive from the left or from the right of the listener. The task of the listener was to detect the approaching car as soon as possible and its direction. He gave his answer by pressing a key of a computer keyboard. Two keys were used : the <Enter> key in the case of a "right" answer, and the <Space> bar for the "left" answer. The response time (from the starting of the stimulus) was measured and stored by the computer.

Each sound was presented 8 times (4 times from each direction) so that a listener was presented 88 stimuli (in a random order).

110 subjects participated to the experiment; among them, 33 were visually-impaired people.

\subsection{Results}

The averaged response time was converted to distance from the listener at detection. These distances are shown in figure 3.

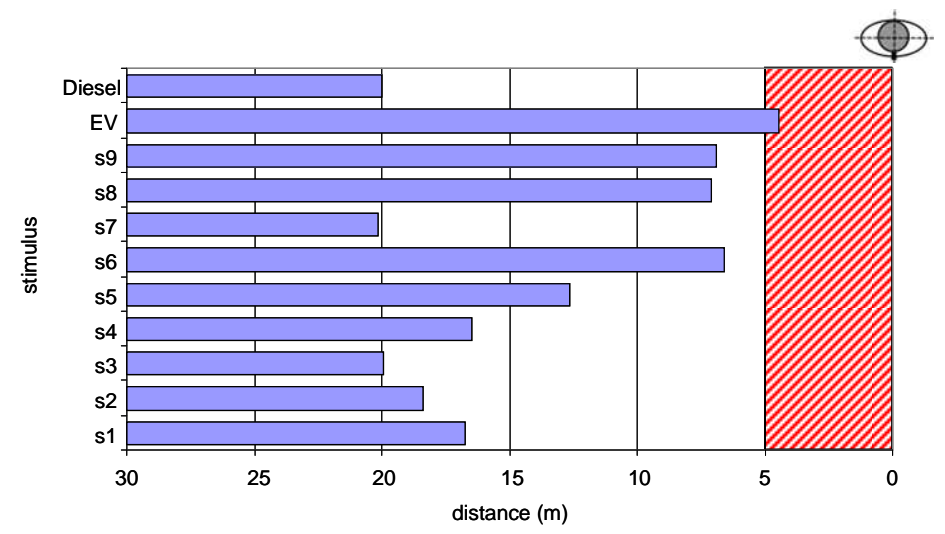

Fig. 3. Averaged distance from the listener at detection. The red area represents the "risk area" (see text). 
In this figure, the "risk area" is represented in red. If the pedestrian starts crossing the road while the car is closer than 5 meters away, he may be hit by the car, given the averaged reaction time needed by the driver to start breaking (Kerber, 2011). The electric vehicle is detected in this area, which confirms that EVs can be dangerous for pedestrians (Glaeser et al., 2012).

Warning sounds had quite different efficiencies, depending on their timbre. Some warning sounds are nearly inefficient (s6, s8 and s9). Some other ones make the EV as easy to detect as the diesel car (s3 and s7). And figure 2 clearly shows that such differences are not related to the level of these sounds - timbre features are the only reason for such differences. Further analysis showed that some controlled features were favorable to detection :

- A low number of tones. The overall sound level was kept constant, so that the difference between each tone level and its detection threshold was greater when the number of tones was low.

- Amplitude modulation. Fluctuations in the signal amplitude helps the listener to detect it in the background of traffic noise.

\section{Sound meaning}

In a second experiment, the question was raised whether it is possible to design the warning sound so as to provide the pedestrian with some information about the distance and the speed of the car. The hypothesis was that a higher pitch and a quicker temporal variation of the warning sound would evoke a faster car.

\subsection{Procedure}

To test this hypothesis, a full experimental design was used. Sounds had three components and a pseudo-random fluctuation of the amplitude, as these characteristics were determined as favorable for detection in the previous experiment. Each factor could have three level, denoted as "low", "mid" or "high". As an exemple, one factor was pitch; the "low" value means $275 \mathrm{~Hz}$, the "mid" one $300 \mathrm{~Hz}$ and the "high" level was $325 \mathrm{~Hz}$. Similarly, the speed of amplitude modulation could have three values. These sounds were synthesized and added to two recordings of a passing-by electric vehicle. One recording was made at $20 \mathrm{~km} / \mathrm{h}$ as in the first experiment and the other one at $30 \mathrm{~km} / \mathrm{h}$. This way, 18 stimuli were created. Two recordings of a diesel car were also used, recorded at the same speed.

These sounds were presented to listeners in a background noise. The level of this noise was lowered as compared to the first experiment ( $64 \mathrm{~dB}(\mathrm{~A})$ instead of $69 \mathrm{~dB}(\mathrm{~A})$ ) so that each approaching car could be easily detected. The task of the listener was to imagine he was going to cross the road in spite of this approaching car. He had to indicated when he thought it was no longer safe to do it, given his appreciation of the speed of the car. Once again, he gave his answer by pressing a key and the response time was stored.

Each sound was repeated four times, giving a number of 80 responses from each listener. 116 people participated to the experiment (77 sighted and 39 visually impaired).

\subsection{Results}

The effect of each factor at each level was computed as the averaged response time for this level subtracted by the grand mean of all data. These effects are shown in figure 4.

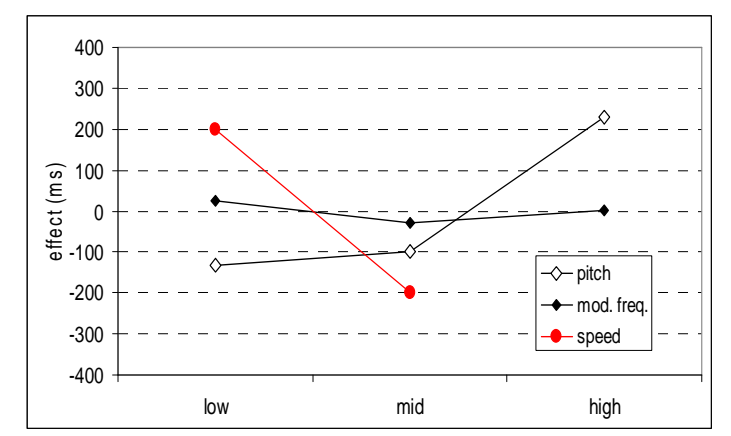

Fig. 4. Factors effects 
The speed effect is clear and natural : people feel unsafe sooner when the car is approaching at $30 \mathrm{~km} / \mathrm{h}$ compared to $20 \mathrm{~km} / \mathrm{h}$. It should be noted that this $10 \mathrm{~km} / \mathrm{h}$ difference is greater than the velocity threshold as mentioned in a previous study from Lutfi and Wang (1999), who measured a threshold of $8 \mathrm{~km} / \mathrm{h}$ at $36 \mathrm{~km} / \mathrm{h}$. But the response time difference between the two speeds is small : $0.4 \mathrm{~s}$. If the response times are converted to distances from the car, averaged values are $14 \mathrm{~m}$ at $20 \mathrm{~km} / \mathrm{h}$ and $10 \mathrm{~m}$ at $30 \mathrm{~km} / \mathrm{h}$. This indicates that listeners clearly detected speeder cars, but underestimated the speed difference.

But results also shown that varying the speed of the temporal fluctuation of the additional sound gives no information to listeners : the effect of this factor is very close to zero, for any of the three levels. And, very surprisingly, the effect of the pitch is that the highest value gives a later response time. This was totally unexpected.

The main conclusion of this experiment is that it seems very unlikely to use the warning sound for conveying some information about the speed of the car which can be understood without any training. The speed of the car is certainly evaluated from the temporal increase of loudness as the car is approaching. Any warning sound will participate to this temporal loudness variation, whatever its characteristics. However, varying the pitch of this sound with the speed of the car may indicate an accelerating (or decelerating car); this was not evaluated by this experiment, as the speed was constant for each stimulus.

\section{Unpleasantness}

\subsection{Procedure}

The third experiment was devoted to the evaluation of the unpleasantness of all warning sounds used in the previous parts of the study. 20 sounds were presented to listeners : the 11 stimuli of experiment 1 and the 9 representing an EV with a warning sound at $20 \mathrm{~km} / \mathrm{h}$ in experiment 2 . The experiment was conducted in two conditions : some listeners were presented the stimuli without any background noise and for some other ones, a low-level traffic noise ( $57 \mathrm{dBA}$ ) was added to each stimulus. In both cases, the task of the listener was to evaluate the unpleasantness of the sound. He gave his answer by moving a cursor on a continuous scale, labeled from "not at all unpleasant" to "extremely unpleasant". The position of the cursor was stored as a number between 0 (for "not at all unpleasant") to 1000 ("extremely unpleasant"). Each sound was presented twice, the order of presentation being randomly selected. 145 people participated to this last experiment, which was conducted in four laboratories.

\subsection{Results}

The repeatability of each listener was evaluated by computing a mean squared difference between the two values he gave for each sound, namely :

$$
C=\sqrt{\frac{1}{20} \sum_{n=1}^{20}\left(x_{n 1}-x_{n 2}\right)^{2}}
$$

where $x_{n 1}$ and $x_{n 2}$ represent the two evaluations of sound $n$.

Individual coefficients range between 50 and 450 (mean value : 179, standard deviation : 65). For 23 subjects, this coefficient is higher than 250 , which represents a full category of the scale : such subjects can be considered as inconsistent. Such a high number of inconsistent subjects means that the task was difficult. So it was decided to select most reliable subjects for further analysis. The maximum value for $\mathrm{C}$ was fixed to 150 , which allowed selecting 56 people. 26 of them did the experiment with the background traffic noise and 30 without this noise.

An analysis of variance was realized (repeated measures, background noise condition as an inter-individual factor and stimuli as intra-individual ones). The only influent factor was stimuli $[\mathrm{F}(19,988)=48.5, \mathrm{p}<0.0001]$. The unpleasantness of each sound was averaged over this subpanel and results are shown in figure 5. Homogeneous groups of sounds are represented by thick horizontal lines (this groups have been determined using Scheffe's technique). 
As it can be seen on figure 5, most warning signals strongly increase the unpleasantness of the sound. This can be due to the fact that people felt very unfamiliar with such warning sounds. Three of them can be considered as equally unpleasant as the diesel car. The particularity of these sounds is that no temporal fluctuation was applied to their amplitude. Amplitude fluctuation increased unpleasantness; the first experiment had shown that it also increased the detectability of sounds. The relation between efficiency and unpleasantness had already been proved for other kinds of warning sounds (Tan and Lerner, 1995, Richir, 2010 or Fagerlönn, 2011).

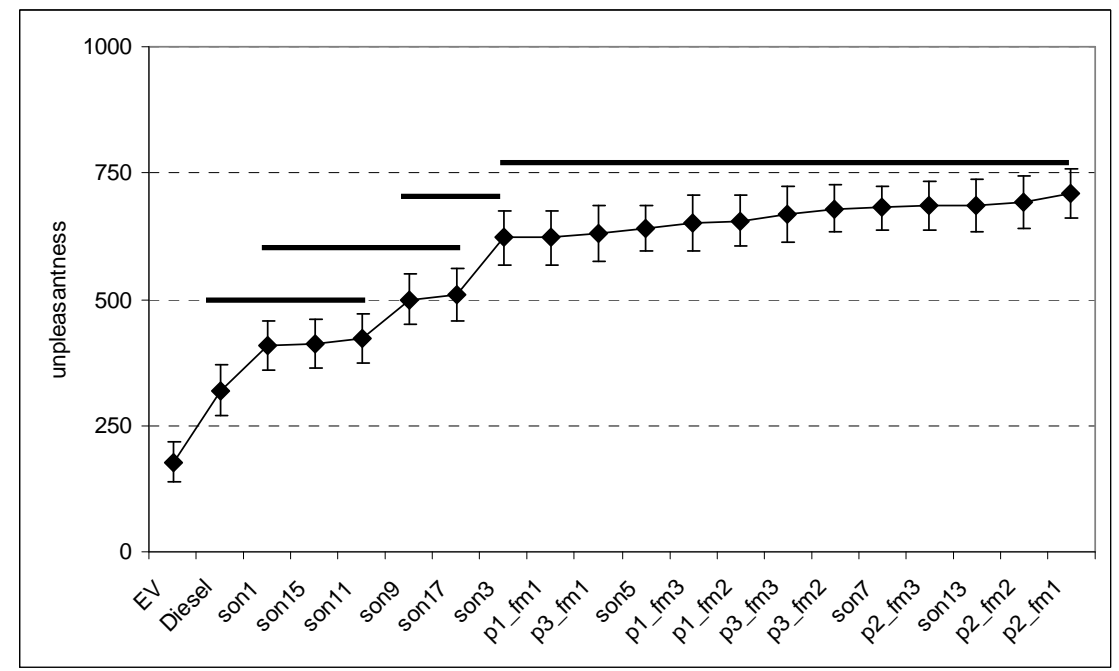

Fig. 5. Unpleasantness of each sound

\section{Conclusion}

This paper presented three experiments aiming at evaluating the influence of basic timbre parameters of a warning signal on its detectability and annoyance. It has been shown that some warning sounds can make an electric vehicle as detectable as a diesel car, for a much lower sound level. Nevertheless, people reported these signals to increase the unpleasantness of the car sound. It is hypothesized that this was due to the unnaturalness of such signals and to their novelty. Further studies during which subjects could get used to such sounds would be useful. Nevertheless, some signals seem to provide a correct compromise between the two objectives.

Finally, it should be recalled that the goal of these studies was not to define a warning signal for a typical application, but to investigate the influence of timbre parameters. This way, it is expected that car manufacturers will have some guidelines when defining their own signal, which should also fulfill some brand image requirements.

\section{Acknowledgements}

The eVADER project is funded by the European Commission, in the frame of the seventh framework program. And the first author is a member of the Labex CeLyA (Lyon Acoustics Center), funded by the French National Research Agency (ANR-10-LABX-60).

\section{References}

Emerson R., Naghshineh K., Kim D., Myers K. (2012). Blind pedestrians and quieter vehicles : how adding artificial sounds impacts travel decision. In Proceedings of Internoise conference (New-York, 2012).

Fagerlönn J. (2010). Urgent alarms in trucks : effects on annoyance and subsequent driving performance. IET Intelligent Transport Systems, available at : http://pure.ltu.se/portal/files/34271457/Johan_Fagerl_nn.pdf. 
Glaeser K.P., Marx T., Schmidt E. Sound dectection of electric vehicles by blind or visually impaired persons. In Proceedings of Internoise conference (New-York, 2012).

Kerber S., Fastl H. Prediction of perceptibility of vehicle exterior noise in background noise. In Proceedings of DAGA conference (Dresden, 2008).

Lutfi R., Wang W. Correlational analysis of acoustic cues for the discrimination of auditory motion. Journal of the Acoustical Society of America 106, 919-928 (1999).

Richir B.A. (2011). Effects of rhythm on the perception of urgency and irritation in auditory signal. MSc thesis Utrecht University. Available at http://igitur-archive.library.uu.nl/student-theses/2010-0907-202354/final thesis bas allein richer 0819.pdf.

Robart R., Parizet E., Chamard J.C., Janssens K., Biancardi F., Schlittenlacher J., Ellermeier W., Pondrom P., Cockram J., Speed-Adrews P., Hatton G. eVADER : a perceptual approach to finding minimum warning sound requirements for quiet cars. In Proceedings of AIA-DAGA conference (Merano, 2013).

Tan A.K., Lerner N.D. (1995). Multiple attribute evaluation of auditory warning signals for in-vehicle crash avoidance warning systems. Report $n^{\circ}$ DOT HS 808 535, National Highway Traffic Safety Administration.

Yamauchi K., Menzel D., Fastl H., Takada M., Nagahata K., Iwamiya S. (2011). Cross-cultural study on feasible sound levels of possible warning sounds for quiet vehicles. In Proceedings of Internoise conference (Osaka, 2011). 